\title{
Breakfast Composition in Junior High School Students
}

\author{
Sheila Devi, ${ }^{1}$ Aly Diana, ${ }^{2}$ Setiawan ${ }^{3}$ \\ ${ }^{1}$ Faculty of Medicine Universitas Padjadjaran, ${ }^{2}$ Department of Medical Nutrition Faculty of \\ Medicine Universitas Padjadjaran, ${ }^{3}$ Department of Physiology Faculty of Medicine Universitas \\ Padjadjaran
}

\begin{abstract}
Background: Adolescence is a time of rapid development that requires higher nutrient intake levels than in adulthood. However the habit of skipping breakfast has become very popular among adolescents. Skipping breakfast has negative effects such as difficulty in concentrating, growth impairment and decrease academic performance. Therefore, this study was conducted to identify the breakfast composisition of early adolescents in Jatinangor, Sumedang, Indonesia.

Methods: A cross sectional study with non-probability sampling method, was conducted in a junior high school Jatinangor during the month of July 2013. Ninety six participants were included in this study. All the participants underwent an interview about the food intake for breakfast in seven days using eating pattern recall guidelines.

Results: Overall, $37 \%$ of the respondents skipped breakfast. The mean of total calories among the adolescents who consumed breakfast was 286.06 (187.89) kcal. The amount of carbohydrate, fat and protein consumed was 29.23 (19.93) gram, 13.93 (13.29) gram and 8.78 (6.11) gram accordingly. The main reason for adolescent to skip breakfast was lack of time.

Conclusions: Majority of the respondents have their breakfast before they go to school. Overall, the total calories comsumed is sufficient however the amount of protein consumed is low. [AMJ.2015;2(4):525-8]
\end{abstract}

Keywords: Adolescent, breakfast habit, breakfast composition

\section{Introduction}

Breakfast is widely being promoted as essential for the nutritional well-being of children and adolescents. ${ }^{1}$ Adolescence is a time of rapid development that requires nutrient intake levels higher than adulthood and behaviors developed during childhood and adolescence are typically carried over into adulthood. ${ }^{2}$ However, breakfast is the meal most often skipped by adolescents. ${ }^{1}$

A study conducted on family and personal predictors reported that skipping breakfast increases with age. ${ }^{1}$ In a study conducted on 540 fourth grade students from selected public schools in Maryland, 20\% reported skipping breakfast three or more times per week. $^{3}$ Breakfast is an important meal of the day because it provides higher energy contributions to the total daily energy intake compare to lunch and dinner. Macronutrient intakes are higher in breakfast consumers in comparison with adolescents who regularly skip breakfast., ${ }^{4,5}$ A study conducted on low income African-American elementary school children showed that children who eat breakfast are more likely to achieve 24-hour dietary adequacy for nutrients than those who has skipped breakfast. ${ }^{6}$ A significantly higher proportion of children skipping breakfast has 24 -hour intakes below $50 \%$ of recommended Dietary Allowance for all nutrients compare to children who eat at breakfast. ${ }^{6}$

The objective of this study was to identify the breakfast composition among selected junior high schools students in Jatinangor, Sumedang, Indonesia

\section{Methods}

This study was conducted at PGRI Junior High School during the month of July 2013. The total number of participants were 100 (40 male and 60 female), selected by using the random sampling method after informed consent was obtained. The participants were selected

Correspondence: Sheila Devi, Faculty of Medicine, Universitas Padjadjaran, Jalan Raya Bandung-Sumedang Km.21, Jatinangor, Sumedang, Indonesia, Phone: +6285721275390 Email: Sheila_d89@hotmail.com 
Table 1 Percentage of Breakfast Consumption

\begin{tabular}{lccc}
\hline \multicolumn{1}{c}{ Category } & Male & Female & Total \\
\cline { 2 - 3 } & $\mathbf{n ( \% )}$ & $\mathbf{n}(\%)$ & 35 \\
\hline Breakfast skippers & $14(39)$ & $21(35)$ & 61 \\
Non breakfast skippers & $22(61)$ & $39(35)$ & 96 \\
Total & 36 & 60 & 96 \\
\hline
\end{tabular}

randomly based on the age from thirteen to fifteen years old. Four students were excluded from this study because of incomplete data and language barrier.

Data on food intake for breakfast in seven days were collected through interviews using eating pattern recall guidelines. The interview was performed by the researcher about the food consumed within one week. The guidelines was validated by the Jatinangor Cohort (Department of Epidemiology Faculty of Medicine, Universitas Padjadjaran).

The guidelines consist of type of food (examples of a meal were given), kind of ingredients of the food (ingredients that were used in the meal), frequency in one week (the number of the same meal taken during seven days) and household measurements (the quantity of food taken in metric measurements, examples include in the form of a teaspoon, a tablespoon and a cup). Furthermore, descriptive statistics was used to calculate the percentage of breakfast skippers and non-breakfast skippers. Breakfast skippers were defined as consuming breakfast less than five times per week, whereas non breakfast skippers were defined as consuming breakfast five times and above. Furthermore, the descriptive statistics is also used to determine the mean and standard deviation of the total calorie, carbohydrate, protein and fat consumed per day. The amount of calorie consumed was calculated using the data from eating pattern recall guidelines and
Nutrisurvey software.

The study was approved by the Health Research Ethics Committee of Faculty of Medicine, Universitas Padjadjaran.

\section{Results}

The percentage of adolescents who skip breakfast was $37 \%$. The number of nonbreakfast skipper respondents was higher compared to breakfast skippers. Furthermore, the proportion of male adolescents who skipped breakfast in Jatinangor was higher than females.

Adolescents in Jatinangor consumed sufficient calories as much as 286.06. They also consumed a high amount of fat and carbohydrate in their breakfast. Although they consumed high amount of fat and carbohydrate, the amount of protein consumed was low.

Compared to all the reasons below, the main reason for the student's to skip breakfast was lack of time. The second reason was laziness and followed by busy lifestyle of parents.

\section{Discussions}

The percentage of adolescent who skipped breakfast was higher in this study (37\%). This result is unlike a previous study in Fiji ${ }^{7}$ on adolescent dietary patterns, where the total percentage of adolescent who skipped breakfast is $24 \%$. In terms of gender, male

Table 2 Nutrient Intake in Breakfast

\begin{tabular}{lcc}
\hline & \multicolumn{2}{c}{ Mean(sd) } \\
\cline { 2 - 3 } & Gram & Kilo calorie \\
\hline Calorie & & $286.06(187.89)$ \\
Protein & $8.78(6.11)$ & $35.10(24.47)$ \\
Fat & $13.93(13.29)$ & $125.43(119.69)$ \\
Carbohydrate & $29.23(19.93)$ & $116.91(79.73)$ \\
\hline
\end{tabular}


Table 3 Reasons for Skipping Breakfast

\begin{tabular}{|c|c|}
\hline Reason & Percentage $(\%)$ \\
\hline Parents are too busy & 18 \\
\hline I am lazy to prepare breakfast & 29 \\
\hline I had no money to buy breakfast & 7 \\
\hline Lack of time & 30 \\
\hline I had no appetite & 4 \\
\hline I prefer to eat lunch and dinner only & 4 \\
\hline Stomach pain & 4 \\
\hline Vomiting problem & 4 \\
\hline
\end{tabular}

adolescents frequently skipped breakfast compared to female (39\%) in this study. Another study in Fiji ${ }^{7}$ showed that females skip breakfast more often than males and this is inconsistent with this study. The gender difference in breakfast consumption is more prominent in adolescent is due to the increase of societal pressures and expectation to be thin in adolescence. ${ }^{4}$ Since females are more likely to practice weight control behaviors, they are more likely to skip breakfast. ${ }^{4}$

According to the Recommended Dietary Intake 2004, a normal healthy person should consume 2400 calories each day (This recommendation is for adult global people, which refer to $80-95 \mathrm{~kg}$ of bodyweight). In this study the breakfast meal provided $12 \%$ of daily energy intake, and the proportion of carbohydrate, protein and fat that contribute to energy in the breakfast was $41 \%, 12 \%$ and $44 \%$ respectively. This result is similar with the study performed on Australian children and adolescents, the breakfast provided 12$19 \%$ of daily energy intakes. ${ }^{8}$ The percentage of contributions to total daily intake of carbohydrate, protein and fat reported were $20 \%, 18 \%$ and $14 \%{ }^{8}$ Compared to the previous study, the adolescents in Jatinangor consumed high carbohydrate, low protein and high amount of fat. They consumed a high fat breakfast which has implications on their health. Studies have found that low fat/ high carbohydrate meals are associated with a decline in fatigue compared to medium fat and high fat breakfast. ${ }^{9}$

A study by Lloyd et al. ${ }^{10}$ reported that mood improved when respondents consumed low fat/high carbohydrate breakfast. High carbohydrate intake in breakfast is associated with more sustained improvement on memory task. Intake of high fat breakfast also can lead to lower satiety. High fat diet is associated with suppression of appetite and food intake. ${ }^{11}$ Beside this, high fat breakfast is found to have higher blood levels of glucose and insulin after eating, which can lead to obesity ${ }^{12}$ Although breakfast is one of the weight control techniques and reduces the risk of obesity over four times, a nutrient composition is important in order to maintain health. ${ }^{4,13}$

Additionally, the main reason for students to skip breakfast was lack of time. This result was consistent with the result reported in Fiji. ${ }^{7}$ The second reason was laziness whereas the third one was that the parents are too busy. A review of 24 studies published in 2009 by Pearson et al. ${ }^{4}$ found that there is relationship between family and breakfast. Parents find it harder to prepare and eat breakfast with their children because of the early morning school bus schedule and non-traditional work hours. ${ }^{4}$ The other reasons are no money to buy breakfast, no appetite, vomiting problem and tendency to have stomach pain. Some of the parents simply cannot afford to provide breakfast for their children. This explains the reason for adolescent to skip breakfast due to lack of money. ${ }^{4}$

There were several limitations in this study. First, since eating pattern recall questionnaire was used in the research, there was a recall bias in this study. The adolescents were not able to recall the frequent food they ate in one week period of time. Recall bias can be minimized by reducing the period of food recall so that the recall period would be as short as possible. The second limitation is that the measurement of nutrient intake was done based on Nutrisurvey software and the value may not be accurate as the value may vary depending on the type of food.

Furthermore, skipping breakfast have 
major implications on adolescents such as nutrient deficiencies, poor physical and mental growth, malnutrition and low immunity. ${ }^{14}$ More emphasis should be placed on breakfast habits especially among adolescents. This study reinforce the role of parents in the development of healthy eating patterns since early adolescents depend on the parents for healthy eating knowledge, attitudes and behaviors. Dietitians need to reinforce the importance of eating breakfast and consumption of healthy breakfast choices. The outcome found in this study also indicated the need for school breakfast programs. This offered potential for improved nutrient intake and academic performance. Hence, schools might be an appropriate venue for promoting good breakfast habits.

In conclusion, the majority of the respondents consume breakfast regularly with sufficient calorie. Adolescents who skip breakfast are more favorable to have diets which are nutritionally inadequate. A future study about correlation between breakfast consumption and nutritional status should be done to identify the role of breakfast in nutritional status among adolescents.

\section{References}

1. Matthys C, De Henauw S, Bellemans M, De Maeyer M, De Backer G. Breakfast habits affect overall nutrient profiles in adolescents. Public Health Nutr. 2006;10(4):413-21.

2. Brown SL, Teufel J, Gautam YR, Norrick C, Birch D. Family and personal predictors of early adolescent eating patterns. Californian J Health Promot. 2012;10:6470.

3. Gross SM, Bronner Y, Welch C, DewberryMoore N, Paige DM. Breakfast and lunch meal skipping patterns among fourthgrade children from selected public schools in urban, suburban, and rural Maryland. J Am Diet Assoc. 2004;104(3):420-423.

4. American Dairy Association and Dairy Council Inc. The nutritional and academic implications of breakfast: supporting methods for increasing breakfast consumption among children and adolescents. New York: American Dairy Association and Dairy Council, Inc; 2009 [cited 2013 November 5] Available from: https://bestpractices.nokidhungry.org/ download/file/fid/465

5. Kuck JM. Differences in dietary patterns by breakfast consumption and weight status in US adolescence. [Thesis]. Ohio: The Ohio State University; 2008.

6. Vereecken C, Dupuy M, Rasmussen M, Kelly C, Nansel TR, Al Sabbah H, et al. Breakfast consumption and its socio-demographic and lifestyle correlates in schoolchildren in 41 countries participating in the HBSC study. Int J Public Health. 2009;54(Suppl 2):180-90.

7. Wate JT, Snowdon W, Millar L, Nichols M, Mavoa H, Goundar R, et al. Adolescent dietary patterns in Fiji and their relationships with standardized body mass index. Int J Behav Nutr phys Act. 2013;10:45.

8. Williams PG. Breakfast and the diets of Australian children and adolescents: an analysis of data from the 1995 National Nutrition Survey. Int J Food Sci Nutr. 2007; 58(3):201-16.

9. Mahoney CR, Taylor HA, Kanarek RB, Samuel P. Effect of breakfast composition on cognitive processes in elementary school children. Physiol Behav. 2005;85(5): 635-45.

10. Lieberman HR, Kanarek RB, ?Prasad C, editors. Nutritional neuroscience. Boca Raton: CRC Press; 2005.

11. Acton QA. Issues in eating disorders, nutrition and digestive medicine. Atlanta, Georgia: Scholarly Editions; 2013.

12. McAllister R. Healthy lunchbox: the working mom's guide to keeping you and your kids trim. Los Angeles: Lifeline Press; 2004.

13. Smith AP. Breakfast and Adult's and Children's Behavior. In: Kanarek RB, Liebermean HR, editors. Diet, brain, behavior: practical implication. Boca Raton: CRC Press; 2012. p. 53-70

14. Onyechi UA, Ugwunnadi G. Comparative study of breakfast intake among school children in urban and rural areas of Nsukka. Animal Research International. 2009;6(1):962-5. 